\title{
The association between elevated serum uric acid levels and islet $\beta$-cell function indexes in newly diagnosed type 2 diabetes mellitus: a cross-sectional study
}

Yimeng Hu ${ }^{1}$, Jie Liu ${ }^{1}$, Huiqiong Li ${ }^{2}$, Hui Zhu ${ }^{3}$, Linjie Liu ${ }^{1}$, Yin Yuan ${ }^{1}$, Jing Chen ${ }^{4}$, Ye Wang ${ }^{1}$, Xuemei Hu ${ }^{1}$, Yancheng Xu Corresp. 1

${ }^{1}$ Department of Endocrinology, Zhongnan Hospital of Wuhan University, Wu Han, Hu Bei, China

Department of Endocrinology, Scholars Group of Colleges, Yi Chang, Hu Bei, China

3 Department of Gerontology, General Hospital of the Yangtze River Shipping, Wu Han, Hu Bei, China

4 Department of Integrated Wards, Zhongnan Hospital of Wuhan University, Wu Han, Hu Bei, China

Corresponding Author: Yancheng Xu

Email address: xycc567@126.com

Background

Serum uric acid (UA) has been reported as a risk factor for type 2 diabetes mellitus (T2DM). However, whether serum UA is associated with insulin resistance and insulin secretion, and the effect of gender on it in the case of the existed association, both remain undefined.

Methods

A cross-sectional study was designed and performed, which enrolled a total of 403 newly diagnosed T2DM patients (mean age, $50.21 \pm 13.34$ years [62.5\% males]). Clinical characteristics and islet function indexes of all participants were analyzed based on gender-specific tertiles of serum UA levels. In addition, multiple linear regression analysis was conducted to investigate covariates associated with islet function indexes.

Results

The mean levels of serum UA were $331.05 \mu \mathrm{mol} / \mathrm{L}$ [interquartile range (IQR): $60.6,400.9$ $\mu \mathrm{mol} / \mathrm{L}$ ] and $267.9 \mu \mathrm{mol} / \mathrm{L}$ (IQR: 204.7, $331.9 \mu \mathrm{mol} / \mathrm{L}$ ) in men and women, respectively. The values of insulin secretion indexes involving AUCins30/glu30, AUCins120/glu120 and total insulin disposition index (DI120) in females were significantly higher than those in males. Apart from the HOMA-IR of men, serum UA was positively associated with insulin secretion and insulin resistance indexes both in men and women. Multivariable linear regression analysis showed serum UA exerted an independent impact on insulin secretion in females, but not on insulin resistance. And in males, islet function was simultaneously affected by serum UA age, BMI and serum lipids.

Conclusions

Serum UA harbored a positive correlation with insulin secretion and insulin resistance 
indexes in newly-diagnosed T2DM patients, which was influenced by gender, BMI, serum lipids. Hence, serum UA may be considered as a predictor for islet function in clinical practice. 
1 The association between elevated serum uric acid levels and islet $\beta$-cell function indexes in

2 newly diagnosed type 2 diabetes mellitus: a cross-sectional study

3 Yimeng $\mathrm{Hu}^{1 \#}$, Jie Liu ${ }^{1 \#}$, Huiqiong $\mathrm{Li}^{2}$, Hui Zhu ${ }^{3}$, Linjie Liu ${ }^{1}$, Yin Yuan ${ }^{1}$, Jing Chen ${ }^{4}$, Ye Wang ${ }^{1}$,

4 Xuemei $\mathrm{Hu}^{1}$, Yancheng $\mathrm{Xu}^{1 *}$

51 Department of Endocrinology, Zhongnan Hospital of Wuhan University, Wuhan, Hubei

6 430071, China

72 Department of Endocrinology, Gezhouba Group Central Hospital, Yichang, Hubei 443002,

8 China

93 Department of Gerontology, General Hospital of the Yangtze River Shipping, Wuhan 430010,

10 China

114 Department of Integrated Wards, Zhongnan Hospital of Wuhan University, Wuhan, Hubei

12 430071, China

13 *Corresponding author: Xu Yancheng E-mail address: xycc567@126.com

14 \# Contributed equally to this work 


\section{Abstract}

\section{Background}

26 Serum uric acid (UA) has been reported as a risk factor for type 2 diabetes mellitus (T2DM).

27 However, whether serum UA is associated with insulin resistance and insulin secretion, and the effect of gender on it in the case of the existed association, both remain undefined.

\section{Methods}

A cross-sectional study was designed and performed, which enrolled a total of 403 newly diagnosed T2DM patients (mean age, 50.21 13.34 years [62.5\% males]). Clinical characteristics and islet function indexes of all participants were analyzed based on gender-specific tertiles of serum UA levels. In addition, multiple linear regression analysis was conducted to investigate covariates associated with islet function indexes.

\section{Results}

36 The mean levels of serum UA were $331.05 \mu \mathrm{mol} / \mathrm{L}$ [interquartile range (IQR): 60.6, 400.9

$37 \mu \mathrm{mol} / \mathrm{L}]$ and $267.9 \mu \mathrm{mol} / \mathrm{L}$ (IQR: 204.7, $331.9 \mu \mathrm{mol} / \mathrm{L}$ ) in men and women, respectively. The values of insulin secretion indexes involving AUCins30/glu30, AUCins120/glu120 and total insulin disposition index (DI120) in females were significantly higher than those in males. Apart

40 from the HOMA-IR of men, serum UA was positively associated with insulin secretion and

41 insulin resistance indexes both in men and women. Multivariable linear regression analysis

42 showed serum UA exerted an independent impact on insulin secretion in females, but not on

43 insulin resistance. And in males, islet function was simultaneously affected by serum UA age, 
44 BMI and serum lipids.

45 Conclusions

46 Serum UA harbored a positive correlation with insulin secretion and insulin resistance indexes in

47 newly-diagnosed T2DM patients, which was influenced by gender, BMI, serum lipids. Hence,

48 serum UA may be considered as a predictor for islet function in clinical practice.

\section{Introduction}

Type 2 Diabetes Mellitus (T2DM) is one of the most prevalent chronic diseases at present,

53

54

55

56

57

58

59

60

61

62

63

64 affecting 415 million adults worldwide (Ogurtsova et al. 2017). The overall prevalence of diabetes is estimated to be $11.6 \%$ in the Chinese adult population ( $\mathrm{Xu}$ et al. 2013). Previous studies have found that serum uric acid (UA) is a potential risk factor for many chronic diseases, such as cardiovascular diseases (Du et al. 2014), hypertension (Kuwabara et al. 2018) and kidney diseases (Giacomo et al. 2012). UA is the product of purine metabolism in humans whose serum concentration depends on dietary intake of purine-containing food and on excretion by urine. Without exception, elevated serum UA has been considered to be closely related to components of metabolic syndrome (MS) in non-diabetic and T2DM populations; thus, the assessment of UA could provide useful information for predicting MS (Nan et al. 2008; Bonakdaran \& Kharaqani 2014). The idea of serum UA as an independent risk factor for T2DM has been debated due to its association with other diabetic risk factors such as obesity (Nan et al. 2007). Yet, an increasing number of studies have provided evidence that UA is positively associated with serum glucose in 
65 healthy and diabetic individuals (Viazzi et al. 2011; Li et al. 2015; Xu et al. 2016).

66 As is known, progressive deterioration of islet $\beta$-cell function and insulin resistance are

67 well-recognized symbols during the development of T2DM in adults. Recent findings suggest

68 that serum UA is the precursor of T2DM rather than the consequence of insulin resistance

69 (Juraschek et al. 2014). Although a number of animal and clinical studies have confirmed that

70 UA plays an important role in the onset of diabetes via oxidative stress and inflammatory

71 processes (Yiginer et al. 2008; Keenan et al. 2012), the association between serum UA with islet

$72 \beta$-cell function is still poorly understood. A previous research has found elevated levels of UA

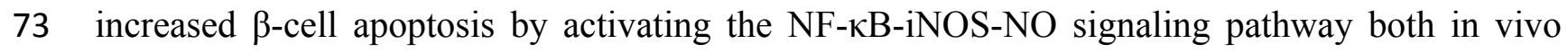

74 and in vitro (Jia et al. 2013). In a clinical study, serum UA has been reported to show a positive

75 relationship with the total phase of insulin secretion (Robles-Cervantes et al. 2011), which is

76 consistent with the conclusion of the Ling 's study (Ling et al. 2012). Together, these studies

77 from different population samples have established an association between serum UA and basal

78 insulin secretion. However, it remains unknown of the effect of serum UA level on different

79 phases of insulin secretion ability and insulin sensitivity in newly diagnosed T2DM patients. And

80 whether there are some other factors collectively influencing islet function requires further

81 investigation.

82 Therefore, we conducted a cross-sectional study to (a) link serum UA levels to islet function

83 indexes in newly diagnosed T2DM patients; (b) examine whether the serum UA levels in T2DM

84 are influenced by age, gender, or body mass index (BMI); and (c) further explore the impact of

85 high serum UA levels on blood pressure, blood lipid profiles and renal function indicators. 
86

87

88

89

90

91

92

93

94

95

96

97

\section{Methods}

\section{Subjects}

In this study, we included Chinese participants aged 20-85 years old who were newly diagnosed with untreated T2DM at Wuhan University Zhongnan Hospital during 2010 to 2017. The diagnosis of T2DM was according to the criteria of the World Health Organization (WHO) (fasting plasma glucose $[\mathrm{FBG}] \geq 7.0 \mathrm{mmol} / \mathrm{L}$ or 2 hour-postprandial plasma glucose $[2 \mathrm{~h}-\mathrm{PBG}]>$ 11.1mmol/L) (Alberti \& Zimmet 1998). A $75 \mathrm{~g}$ oral glucose tolerance test was performed to assess glucose homeostasis and insulin release. To avoid confounding variables, we excluded patients with diabetic micro- and macro-vascular complications, thyroid disease, Cushing syndrome, liver cirrhosis, pheochromocytoma, renal failure, malignant tumors and those who were pregnant or currently taking UA-lowering therapy. A total of 403 participants was enrolled in this study (mean age, $50.21 \pm 13.34$ years $[62.5 \%$ males]). The study protocol was approved by the Ethics Committee of Wuhan University, and all participants signed written informed consent (Ethical Application Ref: 2016019).

\section{Measurements}

Study participants were inquired about their age, family history, alcohol consumption, smoking, and past medical conditions. Body mass index (BMI) was calculated as weight in kilograms divided by the height in meters squared $\left(\mathrm{kg} / \mathrm{m}^{2}\right)$. Normal weight, overweight, and obesity were defined as BMI $<23 \mathrm{~kg} / \mathrm{m}^{2}$, BMI: $23.0-24.9 \mathrm{~kg} / \mathrm{m}^{2}$ and BMI $\geq 25 \mathrm{~kg} / \mathrm{m}^{2}$ for Asian population, respectively, according to Asian-Pacific WHO BMI criteria (Consultation 2004).

Participants' seated blood pressure was measured by trained nurses on the left arm with a 
107 sphygmomanometer upon initial examination. Overnight fasting blood samples were collected

108 from the antecubital vein of each individual to test for serum total cholesterol (TC), triglycerides

109 (TG), high-density lipoprotein-cholesterol (HDL-c), low-density lipoprotein-cholesterol (LDL-c),

110 blood urea nitrogen (BUN), serum creatinine (Scr) and uric acid (UA) levels. All parameters

111 were analyzed by the standardized enzymatic method.

\section{OGTT and Insulin releasing test (IRT)}

After a 12-16 hour, overnight fast, patients were administered with a 75-g glucose solution.

114 Blood samples were collected from the antecubital vein at $0,30,60,120$, and 180 min intervals

115 to measure plasma glucose (FBG, Glu30, Glu60, Glu120, Glu180) and serum insulin (Ins0, Ins30,

116 Ins60, Ins120, Ins 180). Plasma glucose was evaluated with the glucose oxidase method, and the

117 serum insulin level was determined by chemiluminescent enzyme immunoassay.

\section{Calculation of islet function indexes}

119 Insulin sensitivity was evaluated based on the homeostasis model assessment insulin 120 resistance (HOMA-IR) and insulin sensitivity index (ISI) composite (Matsuda \& DeFronzo

121 1999). HOMA- $\beta$ provided an index to measure basic insulin secretion, whereas the area under

122 the curve of insulin-to-glucose ratio (AUC insulin/glucose) reflected insulin response to glucose

123 at different times. Here, the value of the AUC was calculated using the trapezoid method. In

124 consideration of the effect of insulin sensitivity on these indexes, several researchers developed

125 the early-phase insulin disposition index (DI30) and the total insulin disposition index (DI120) to

126 assess insulin secretion with respect to insulin sensitivity (Utzschneider et al. 2009; Ram et al.

127 2015). 
128

129

130

131

132

133

134

135

136

137

138

139

140

141

142

143

144

145

146

147

148

To evaluate islet $\beta$-cell function, the insulin sensitivity indexes and insulin secretion indexes were calculated; and their formulas are as follows:

$$
\text { HOMA-IR }=\text { Fins } \times \text { FPG/22.5 }
$$

$$
\text { ISI-composite }=10000 /\left(\text { mean } \mathrm{Glu}_{0-120} \times \text { mean } \operatorname{Ins}_{0-120} \times \mathrm{FBG} \times \operatorname{Ins} 0\right)^{0.5} .
$$

HOMA- $\beta=(20 \times \operatorname{Ins} 0) /($ FPG-3.5).

$$
\text { AUCins30/glu30= AUCins30/AUCglu30. }
$$

$$
\text { AUCins120/glu120 = AUCins120/AUCglu120. }
$$

DI30= AUCins30/glu30 $\times$ ISI-composite (Retnakaran et al. 2009).

$$
\text { DI120= AUCins120/glu120 ×ISI-composite (Retnakaran et al. 2009). }
$$

\section{Statistical analysis}

Men and women have different average serum UA levels, so we analyzed these two groups separately throughout the study. Sex-specific tertiles of serum UA $(\mu \mathrm{mol} / \mathrm{L})$ were established in men/women as following: first tertile: $\leq 279.7 / 224.1 \mu \mathrm{mol} / \mathrm{L}$, second tertile: $279.7-368.6 / 224.1$ $311.7 \mu \mathrm{mol} / \mathrm{L}$, and third tertile: $\geq 368.8 / 311.7 \mu \mathrm{mol} / \mathrm{L}$. All continuous variables were presented as the mean $\pm \mathrm{SD}$ or as median and interquartile range, and all categorical variableswere presented as a number (proportion). A chi-square test $\left(\chi^{2}\right)$ was used for among-groups comparisons of normally distributed data for categorical variables. A Student's t-test, ANOVA, or the Wilcoxon rank-sum test was used for among-groups comparisons of skewed data. Tukey's test was performed to analyze the difference between the two groups. Lastly, the Pearson and Spearman correlation test was utilized to determine the simple correlation between serum UA levels and islet function indexes. To evaluate whether serum UA was an independent risk factor for 
149 deterioration of islet function in T2DM, we performed a stepwise multiple linear regression

150 analysis was performed by adjusting for potential confounding factors of islet function. A two-

151 tailed $\mathrm{p} \leq 0.05$ was considered as statistically significant. All statistical analyses were performed

152 using SPSS software (version 21.0; SPSS, Chicago, IL, USA) and Origin software (version 8.0;

153 Originlab, Northampton, MA, USA).

\section{Results}

155 The demographic and clinical characteristics of the 403 newly-diagnosed T2DM patients

156 were shown in Table.1. Briefly, there were 252 males and 151 females. The mean age of all

157 participants was $50.21 \pm 13.34$ years old. The men were younger $(47.97 \pm 13.09$ vs. $53.95 \pm$

15812.96 years, $\mathrm{P}<0.001)$ and had a higher prevalence of smoking $(42.5 \% \mathrm{vs} .6 \%, \mathrm{P}<0.001)$ and

159 alcohol consumption $(27.8 \%$ vs. $3 \%, \mathrm{P}<0.001)$ in comparison to the women. Serum UA levels

160 and values of BMI, DBP, FBG, BUN and Scr were significantly higher in men than those in

161 women (all $\mathrm{P}<0.05$ ). Compared with females, males had a significantly lower value of HDL-c

162 [0.94 (IQR: 0.84, 1.07) vs.1.11 (IQR: 0.95, 1.33) mmol/L, P < 0.001]. There were no gender-

163 specific differences in SBP, 2hPBG, TC, TG, LDL-c, HbA1c, and family history of T2DM.

164 To comprehensively evaluate islet function, insulin sensitivity and secretion indices were

165 calculated in all participants. As shown in Table.2, compared with females, males had 166 significantly lower values of AUCins30/glu30, AUCins120/glu120 and DI120. The values of

167 HOMA-IR, ISI-composite, HOMA- $\beta$ and DI30 were not significantly different between the two 168 groups.

169 The distributions of clinical characteristics and islet function indexes of study subjects 
170 based on gender-specific tertiles of serum UA levels were presented in Table.3 and Table.4,

171 respectively.Across male serum UA tertiles, SBP, DBP, LDL-c, HDL-c, BUN, family history of

172 T2DM, smoking and alcohol consumption did not differ significantly while all other variables

173 differed significantly. Specifically, compared to those in the first tertile, males in the third tertile

174 were younger, had signficantly higher BMI, increased values of TC, TG and Scr, and more

175 decreased values of FBG and 2hPBG. Compared with those in the second tertile, the values of

176 TC, TG and Scr were increased in the third tertile. Moreover, apart from age and Scr, there was

177 no difference between the first tertile and the second tertile in terms of clinical characteristics.

178 The analyses of islet function indexes suggested that there was no significant difference with

179 HOMA-IR among the three tertiles; however, it did show a slightly increasing trend with

180 increasing serum UA levels. Furthermore, HOMA- $\beta$, AUCins30/glu30, AUCins120/glu120,

181 DI30 and DI120 all significantly increased while ISI-composite significantly decreased with

182 ascending serum UA tertiles. In female participants, there was no significant difference with

183 respect to age, 2hPBG, TC, LDL-c, family history of T2DM, smoking and alcohol consumption

184 among tertiles. The values for BMI, SBP, DBP, BUN and Scr of the third tertile in females were

185 significantly higher than those in the first tertile, whereas the values for FBG and HDL were

186 significantly lower. For islet function indexes, HOMA-IR, HOMA- $\beta$, AUCins30/glu30,

187 AUCins120/glu120, DI30 and DI120 rose significantly as serum UA increased in women. In

188 accordance with the above results, the value of ISI-composite of the females in the third tertile

189 was lower than that in the first tertile.

190 The correlations between serum UA levels and each islet function index by gender were 
191 exhibited in Table.5. In men, serum UA was positively associated with HOMA- $\beta(\mathrm{r}=0.32, \mathrm{P}<$ 192 0.01), AUCins30/glu30 ( $\mathrm{r}=0.33, \mathrm{P}<0.01)$, AUCins120/glu120 ( $\mathrm{r}=0.35, \mathrm{P}<0.01)$, DI30 ( $\mathrm{r}=$ $1930.22, \mathrm{P}<0.01)$ and DI120 $(\mathrm{r}=0.26, \mathrm{P}<0.01)$, and was negatively related to ISI-composite $(\mathrm{r}=$ 194 0.24, P $<0.01)$. Also, serum UA was not significantly associated with HOMA-IR. In women, 195 serum UA had positive associations with HOMA-IR $(\mathrm{r}=0.22, \mathrm{P}<0.01)$, HOMA- $\beta(\mathrm{r}=0.28, \mathrm{P}<$ 196 0.01), AUCins30/glu30 ( $\mathrm{r}=0.32, \mathrm{P}<0.01)$, AUCins120/glu120 ( $\mathrm{r}=0.33, \mathrm{P}<0.01)$, DI30 ( $\mathrm{r}=$ $1970.19, \mathrm{P}=0.02)$ and DI120 $(\mathrm{r}=0.22, \mathrm{P}<0.01)$ and a negative correlation with ISI-composite $(\mathrm{r}=$ $198-0.31, \mathrm{P}<0.01)$.

199 To identify confounding factors affecting islet function, multiple linear regression analysis 200 was performed on the above-mentioned indexes. Independent variables such as UA, age, BMI, 201 SBP, DBP, TC, TG, HDL-c, LDL-c BUN, Scr, family history, smoking and alcohol consumption 202 were enrolled. In males, the regression equation of HOMA-IR was not statistically significant. 203 The remaining regression equations exhibited significance and the results were shown in Table.6. 204 BMI $(\beta=-0.26, \mathrm{P}<0.01)$, while negatively associated with ISI-composite and $\operatorname{Scr}(\beta=0.134, \mathrm{P}$ $205=0.03$ ), solely produced a positive effect on HOMA- $\beta$. Moreover, value of AUCins30/glu30 was 206 positively influenced by UA $(\beta=0.241, \mathrm{P}<0.01), \mathrm{BMI}(\beta=0.188, \mathrm{P}<0.01), \mathrm{DBP}(\beta=0.129, \mathrm{P}$ $207<0.01)$ and age $(\beta=0.128, \mathrm{P}<0.01)$. Similarly, AUCins120/glu120 was jointly affected by the 208 four factors mentioned above $(\beta=0.334,0.169,0.174,0.122$, respectively) and was negatively 209 affected by TG $(\beta=-0.151, \mathrm{P}<0.01)$. Additionally, UA, SBP and Scr were positive influencing 210 factors for both DI30 ( $\beta=0.2160 .1230 .158$, respectively) and DI120 ( $\beta=0.272,0.139,0.149$, 211 respectively), while serum TC was a negative influencing factor for both of the indexes $(\beta=-$ 
2120.185 and $\beta=-0.181$, respectively). As shown in Table.7, no variable entered into the equation

213 of HOMA- $\beta$ and DI30 in women. Notably, serum UA concentration independently affected

214 AUCins30/glu30 $(\beta=0.263, \mathrm{P}<0.01)$, AUCins120/glu120 $(\beta=0.296, \mathrm{P}<0.01)$ and DI120 $(\beta=$

$2150.191, \mathrm{P}=0.03)$, while BMI independently affected HOMA-IR $(\beta=0.308, \mathrm{P}<0.01)$ and ISI-

216 composite $(\beta=-0.422, \mathrm{P}<0.01)$.

217 Multivariable linear regression analysis indicated that BMI also played an important role in

218 islet function both in men and women. All participants were divided into three groups: normal

219 weight, overweight and obesity, followd by calculation of the seven islet function indexes. As

220 shown in Table.8, the values of serum UA levels, HOMA-IR, HOMA- $\beta$, AUCins30/glu30,

221 AUCins120/glu120 and DI30 of the obesity group in males were significantly higher than those

222 in the normal weight group, whereas the value ISI-composit was significantly lower. In female

223 participants, serum UA levels, HOMA-IR, HOMA- $\beta$, AUCins30/glu30, AUCins120/glu120,

224 DI30 and DI120 all significantly increased, while ISI-composite significantly decreased with

225 increasing BMI values.

226 Discussion

227 In this population-based study of newly diagnosed T2DM in Chinese participants, we found

228 that the values of AUCins30/glu30 and AUCins120/glu120 were higher in females than in males.

229 AUCins/glu denotes the levels of insulin secretion and DI represents the ability of islet $\beta$-cells to

230 compensate against insulin resistance. There was no significant difference between men and

231 women in insulin sensitivity. In agreement with our results, a previous study demonstrated

232 higher insulin secretion in women and similar insulin sensitivity among women and men of a 
233 normal glucose tolerance population (Clausen et al. 1996). This phenomenon may be explained

234 by the ability of female hormones to facilitate the adaptive increase of insulin biosynthesis,

235 glucose stimulated insulin secretion (GSIS) and islet $\beta$-cell mass (Nadal et al. 2009).

236 Theoretically, increased insulin secretion could compensate for insulin resistance and could

237 maintain normal plasma glucose levels for 10 years before the onset of clinical T2DM (Reaven

238 2009). There are two phases of insulin secretion that occur in individuals with normal glucose

239 tolerance: the early phase and the basal phase. Early-phase insulin secretion declines and even

240 disappears in T2DM patients, suggesting that early-phase insulin secretion is very sensitive to

241 glucotoxicity (Kahn et al. 2001). Moreover, the degree of basal insulin secretion impairment is

242 consistent with increased plasma glucose levels, indicating that basal insulin secretion is the

243 main influencing factor on the plasma glucose levels (Lin et al. 2010). Our results that the value

244 of DI120 in females was higher than that in males suggested a slower deterioration of $\beta$-cells in

245 females. This might explain why the control of FBG levels in women is superior to that in men.

246 Hyperuricemia has been regarded as an independent risk factor for cerebrovascular disease,

247 and it is also a powerful and optimal predictor for cardiovascular events in diabetic patients

248 (Verdoia et al. 2014). Still, an independent relationship between serum UA and islet dysfunction

249 has never been confirmed. In our study, insulin resistance and insulin secretion increased with

250 rising serum UA levels in both men and women. After adjusting for confounding factors

251 influencing islet function, serum UA was associated with AUCins30/glu30, AUCins120/glu120,

252 DI30 and DI120 in males. Meanwhile, serum UA independently affected AUCins30/glu30,

253 AUCins120/glu120 and DI120 in females. Together, these results indicate that serum UA plays a 
254 more important role in augmenting insulin secretion rather than in insulin resistance.

255 With regards to the mechanism underlying the effect of serum UA on insulin resistance and 256 insulin secretion, there is no definite explanation despite numerous animal and clinical studies.

257 Previous studies have suggested that hyperuricemia and insulin resistance mutually promote each

258 other. Specifically, hyperinsulinemia facilitates the re-absorption of urate and $\mathrm{Na}^{+}$in the brush

259 border membranes of the renal proximal tubule (Enomoto et al. 2002). In addition, high serum

260 insulin could reduce the clearance rate of urate and caused imbalances in human purine

261 metabolism by increasing hepatic de-novo lipogenesis (Flannery et al. 2012). In the present study,

262 the levels of Scr were increased with rising serum UA tertiles, showing that insulin resistance

263 decreased urate renal clearance. In turn, it is acceptable that oxidative stress and inflammation

264 can also be a source of hyperuricemia, which subsequently worsens insulin resistance.

265 Hyperuricemia leads to the reduction of endogenous nitric oxide (eNO) and the injury of

266 endothelial cells, which directly results in oxidative stress and inflammation of adipoctyes and is

267 involved in insulin resistance (Feron et al. 1999). It has been reported that hyperuricemia inhibits

268 proliferation of islet $\beta$-cells and induces oxidative damage by activating adenosine

269 monophosphate-activated protein kinase (AMPK) and extracellular signal-regulated kinase

270 signal (ERK) pathways (Zhang et al. 2013). In consideration of the association between serum

271 UA and insulin secretion, some studies have reported that high serum UA impairs insulin

272 secretion in rat models (Scott et al. 1981; Rocic et al. 2005), however, more researches including

273 our study conclude that serum UA augments insulin secretion, particularly basal insulin secretion.

274 These results may be interpreted as existed differences between rodents and humans. 
275 Hyperuricemia induces increased insulin secretion to compensate for insulin resistance. There is

276 a study finding that hyperuricemic patients have increased levels of atrial natriuretic peptide

277 (ANP) and brain natriuretic peptide (BNP), hence, the beneficial effect of ANP levels on islet $\beta$ -

278 cell could not be excluded (Hermans et al. 2009). Furthermore, antioxidant properties of serum

279 UA protect islet $\beta$-cell function from oxidative stress, which might, thereby, improve islet

280 neogenesis and islet cell apoptosis. As many studies have been undertaken to obtain a better

281 understanding of the complex molecular mechanisms inducing insulin secretion and insulin

282 resistance (Ohneda et al. 2000; Arcidiacono et al. 2014), the effect of serum UA on potential

target genes and pathways of insulin production will provide novel research directions for our

284 further investigation.

285 In this study, we also observed that BMI showed significant differences among the three

286 UA tertiles in both men and women. As shown in Table.8, with the obese cohort, insulin

287 resistance was more evident than that in the normal weight group, in spite of the more evident

288 two-phase insulin secretion. These results are compatible with the hyperinsulinemic conditions

289 that characterize insulin resistance states. However, consistent with our results, another study has

290 showed a greater potential in the recovery of islet function in part of obese population (Shetty et

291 al. 2012). Consequently, for obese T2DM patients, the primary goal is to improve insulin

292 sensitivity by weight loss. Previous studies have reported that improvement of insulin sensitivity

293 and delay of progression of T2DM could be observed after a modest calorie restriction and

294 weight reduction (Greco et al. 2014; Grams \& Garvey 2015). In addition, in males, TC and TG

295 negatively affected insulin secretion indexes. An 8-year longitudinal study involving non-elderly 
296 people has showed that dyslipidemia and high blood pressure are associated with insulin

297 resistance, and VLDL-cholesterol are correlated with impaired early phase insulin secretion

298 (Kekalainen et al. 2000).

299 There were several limitations in this study. First, there were limitations to the analysis of

300 disease risk from a causal relationship. Second, potential variables, which would affect islet

301 function, such as exercise, education, profession, and energy intake, were not taken into

302 consideration. However, the large-scale population-based ensured convincing outcomes of

303 investigating the interaction of the serum UA and islet function, and we speculated about

304 potential molecular mechanisms by which UA affects islet function. Second, to the best of our

305 knowledge, it was the first study that used seven indexes to comprehensively reflect the different

306 phases of insulin secretion and insulin sensitivity. Third, we also analyzed the other risk factors

307 influencing islet function.

\section{Conclusions}

309 Serum UA harbored a positive correlation with insulin secretion and insulin resistance

310 indexes in newly-diagnosed T2DM patients, which was influenced by age, BMI, and serum

311 lipids. Hence, serum UA may be considered as a predictor for islet function in clinical settings.

312

\section{$313 \quad$ References}

314 Ogurtsova K, da Rocha Fernandes JD, Huang Y, Linnenkamp U, Guariguata L, Cho NH, Cavan D, 315 Shaw JE, and Makaroff LE. 2017. IDF Diabetes Atlas: Global estimates for the prevalence of diabetes for 2015 and 2040. Diabetes Res Clin Pract 128:40-50. 10.1016/j.diabres.2017.03.024

318 Xu Y, Wang L, He J, Bi Y, Li M, Wang T, Wang L, Jiang Y, Dai M, and Lu J. 2013. Prevalence and 
319

320

321

322

323

324

325

326

327

328

329

330

331

332

333

334

335

336

337

338

339

340

341

342

343

344

345

346

347

348

349

350

351

352

353

354

355

356

357

358

359

control of diabetes in Chinese adults. Jama 310:948.

Du T, Sun X, Lu H, Lin X, Liu Q, Huo R, and Yu X. 2014. Associations of serum uric acid levels with cardiovascular health factors: differences by sex, age and body mass index in Chinese participants. Eur J Intern Med 25:388-393. 10.1016/j.ejim.2014.03.004

Kuwabara M, Hisatome I, Niwa K, Hara S, Roncal-Jimenez CA, Bjornstad P, Nakagawa T, AndresHernando A, Sato Y, Jensen T, Garcia G, Rodriguez-Iturbe B, Ohno M, Lanaspa MA, and Johnson RJ. 2018. Uric Acid Is a Strong Risk Marker for Developing Hypertension From Prehypertension: A 5-Year Japanese Cohort Study. Hypertension 71:78-86. 10.1161/hypertensionaha.117.10370

Giacomo Z, Giovanni T, Michel C, Vittorio O, Cataldo A, Isabella P, Carlo N, and Enzo B. 2012. Serum Uric Acid Levels and Incident Chronic Kidney Disease in Patients With Type 2 Diabetes and Preserved Kidney Function. Diabetes Care 35:99.

Nan H, Qiao Q, Soderberg S, Gao W, Zimmet P, Shaw J, Alberti G, Dong Y, Uusitalo U, Pauvaday V, Chitson P, and Tuomilehto J. 2008. Serum uric acid and components of the metabolic syndrome in non-diabetic populations in Mauritian Indians and Creoles and in Chinese in Qingdao, China. Metab Syndr Relat Disord 6:47-57. 10.1089/met.2007.0028

Bonakdaran S, and Kharaqani B. 2014. Association of serum uric acid and metabolic syndrome in type 2 diabetes. Curr Diabetes Rev 10:113-117.

Nan H, Dong Y, Gao W, Tuomilehto J, and Qiao Q. 2007. Diabetes associated with a low serum uric acid level in a general Chinese population. Diabetes Res Clin Pract 76:68-74. 10.1016/j.diabres.2006.07.022

Viazzi F, Leoncini G, Vercelli M, Deferrari G, and Pontremoli R. 2011. Serum uric acid levels predict new-onset type 2 diabetes in hospitalized patients with primary hypertension: the MAGIC study. Diabetes Care 34:126-128. 10.2337/dc10-0918

Li YL, Xie H, Musha H, Xing Y, Mei CX, Wang HJ, and Wulasihan M. 2015. The Risk Factor Analysis for Type 2 Diabetes Mellitus Patients with Nonalcoholic Fatty Liver Disease and Positive Correlation with Serum Uric Acid. Cell Biochem Biophys 72:643-647. 10.1007/s12013014-0346-1

Xu YL, Xu KF, Bai JL, Liu Y, Yu RB, Liu CL, Shen C, and Wu XH. 2016. Elevation of serum uric acid and incidence of type 2 diabetes: A systematic review and meta-analysis. Chronic Dis Transl Med 2:81-91. 10.1016/j.cdtm.2016.09.003

Juraschek SP, McAdams-Demarco M, Miller ER, Gelber AC, Maynard JW, Pankow JS, Young H, Coresh J, and Selvin E. 2014. Temporal relationship between uric acid concentration and risk of diabetes in a community-based study population. Am J Epidemiol 179:684-691. 10.1093/aje/kwt320

Yiginer O, Ozcelik F, Inanc T, Aparci M, Ozmen N, Cingozbay BY, Kardesoglu E, Suleymanoglu S, Sener G, and Cebeci BS. 2008. Allopurinol improves endothelial function and reduces oxidant-inflammatory enzyme of myeloperoxidase in metabolic syndrome. Clin Res Cardiol 97:334-340. 10.1007/s00392-007-0636-3

Keenan T, Blaha MJ, Nasir K, Silverman MG, Tota-Maharaj R, Carvalho JA, Conceicao RD, Blumenthal RS, and Santos RD. 2012. Relation of uric acid to serum levels of high- 
360

361

362

363

364

365

366

367

368

369

370

371

372

373

374

375

376

377

378

379

380

381

382

383

384

385

386

387

388

389

390

391

392

393

394

395

396

397

398

399

400 sensitivity C-reactive protein, triglycerides, and high-density lipoprotein cholesterol and to hepatic steatosis. Am J Cardiol 110:1787-1792. 10.1016/j.amjcard.2012.08.012

Jia L, Xing J, Ding Y, Shen Y, Shi X, Ren W, Wan M, Guo J, Zheng S, Liu Y, Liang X, and Su D. 2013. Hyperuricemia causes pancreatic beta-cell death and dysfunction through NF-kappaB signaling pathway. PLoS One 8:e78284. 10.1371/journal.pone.0078284

Robles-Cervantes JA, Ramos-Zavala MG, Gonzalez-Ortiz M, Martinez-Abundis E, ValenciaSandoval C, Torres-Chavez A, Espinel-Bermudez C, Santiago-Hernandez NJ, and Hernandez-Gonzalez SO. 2011. Relationship between Serum Concentration of Uric Acid and Insulin Secretion among Adults with Type 2 Diabetes Mellitus. Int J Endocrinol 2011:107904. 10.1155/2011/107904

Ling Y, Li XM, Gu Q, and Gao X. 2012. [Correlation of serum uric acid and islet beta cell functions in female type 2 diabetics]. Zhonghua Yi Xue Za Zhi 92:541-545.

Alberti KG, and Zimmet PZ. 1998. Definition, diagnosis and classification of diabetes mellitus and its complications. Part 1: diagnosis and classification of diabetes mellitus provisional report of a WHO consultation. Diabet Med 15:539-553. 10.1002/(sici)10969136(199807)15:7<539::aid-dia668>3.0.co;2-s

Consultation WE. 2004. Appropriate body-mass index for Asian populations and its implications for policy and intervention strategies. Lancet 363:157-163. 10.1016/s01406736(03)15268-3

Matsuda M, and DeFronzo RA. 1999. Insulin sensitivity indices obtained from oral glucose tolerance testing: comparison with the euglycemic insulin clamp. Diabetes Care 22:1462-1470.

Utzschneider KM, Prigeon RL, Faulenbach MV, Tong J, Carr DB, Boyko EJ, Leonetti DL, McNeely MJ, Fujimoto WY, and Kahn SE. 2009. Oral disposition index predicts the development of future diabetes above and beyond fasting and 2-h glucose levels. Diabetes Care 32:335341. $10.2337 / \mathrm{dc0} 8-1478$

Ram J, Snehalatha C, Selvam S, Nanditha A, Shetty AS, Godsland IF, Johnston DG, and Ramachandran A. 2015. The oral disposition index is a strong predictor of incident diabetes in Asian Indian prediabetic men. Acta Diabetol 52:733-741. 10.1007/s00592015-0718-z

Retnakaran R, Qi Y, Goran MI, and Hamilton JK. 2009. Evaluation of proposed oral disposition index measures in relation to the actual disposition index. Diabet Med 26:1198-1203. 10.1111/j.1464-5491.2009.02841.x

Clausen JO, Borch-Johnsen K, Ibsen H, Bergman RN, Hougaard P, Winther K, and Pedersen O. 1996. Insulin sensitivity index, acute insulin response, and glucose effectiveness in a population-based sample of 380 young healthy Caucasians. Analysis of the impact of gender, body fat, physical fitness, and life-style factors. J Clin Invest 98:1195-1209. 10.1172/jci118903

Nadal A, Alonso-Magdalena P, Soriano S, Ropero AB, and Quesada I. 2009. The role of oestrogens in the adaptation of islets to insulin resistance. J Physiol 587:5031-5037. 10.1113/jphysiol.2009.177188 
401 Reaven GM. 2009. HOMA-beta in the UKPDS and ADOPT. Is the natural history of type 2

402

403

404

405

406

407

408

409

410

411

412

413

414

415

416

417

418

419

420

421

422

423

424

425

426

427

428

429

430

431

432

433

434

435

436

437

438

439

440

441 diabetes characterised by a progressive and inexorable loss of insulin secretory function? Maybe? Maybe not? Diab Vasc Dis Res 6:133-138. 10.1177/1479164109336038

Kahn SE, Montgomery B, Howell W, Ligueros-Saylan M, Hsu CH, Devineni D, McLeod JF, Horowitz A, and Foley JE. 2001. Importance of early phase insulin secretion to intravenous glucose tolerance in subjects with type 2 diabetes mellitus. J Clin Endocrinol Metab 86:5824-5829. 10.1210/jcem.86.12.8105

Lin JD, Hsia TL, Wu CZ, Su CC, Ma WY, Hsieh AT, Hsieh CH, Wang K, Chu YM, and Pei D. 2010. The first and second phase of insulin secretion in naive Chinese type 2 diabetes mellitus. Metabolism 59:780-786. 10.1016/j.metabol.2009.09.024

Verdoia M, Barbieri L, Schaffer A, Cassetti E, Nardin M, Bellomo G, Aimaretti G, Marino P, Sinigaglia $F$, and De Luca G. 2014. Impact of diabetes on uric acid and its relationship with the extent of coronary artery disease and platelet aggregation: a single-centre cohort study. Metabolism 63:640-646. 10.1016/j.metabol.2014.01.010

Enomoto A, Kimura H, Chairoungdua A, Shigeta Y, Jutabha P, Cha SH, Hosoyamada M, Takeda M, Sekine T, Igarashi T, Matsuo H, Kikuchi Y, Oda T, Ichida K, Hosoya T, Shimokata K, Niwa T, Kanai Y, and Endou H. 2002. Molecular identification of a renal urate anion exchanger that regulates blood urate levels. Nature 417:447-452. 10.1038/nature742

Flannery C, Dufour S, Rabol R, Shulman GI, and Petersen KF. 2012. Skeletal muscle insulin resistance promotes increased hepatic de novo lipogenesis, hyperlipidemia, and hepatic steatosis in the elderly. Diabetes 61:2711-2717. 10.2337/db12-0206

Feron O, Dessy C, Moniotte S, Desager JP, and Balligand JL. 1999. Hypercholesterolemia decreases nitric oxide production by promoting the interaction of caveolin and endothelial nitric oxide synthase. J Clin Invest 103:897-905. 10.1172/jci4829

Zhang Y, Yamamoto T, Hisatome I, Li Y, Cheng W, Sun N, Cai B, Huang T, Zhu Y, Li Z, Jing X, Zhou $\mathrm{R}$, and Cheng J. 2013. Uric acid induces oxidative stress and growth inhibition by activating adenosine monophosphate-activated protein kinase and extracellular signalregulated kinase signal pathways in pancreatic beta cells. Mol Cell Endocrinol 375:89-96. 10.1016/j.mce.2013.04.027

Scott FW, Trick KD, Stavric B, Braaten JT, and Siddiqui Y. 1981. Uric acid-induced decrease in rat insulin secretion. Proc Soc Exp Biol Med 166:123-128.

Rocic B, Vucic-Lovrencic M, Poje N, Poje M, and Bertuzzi F. 2005. Uric acid may inhibit glucoseinduced insulin secretion via binding to an essential arginine residue in rat pancreatic beta-cells. Bioorg Med Chem Lett 15:1181-1184. 10.1016/j.bmcl.2004.12.003

Hermans MP, Ahn SA, and Rousseau MF. 2009. Raised natriuretic peptides, big-endothelin-1 and improved beta-cell function in type 2 diabetic males with hyperuricaemia. Diab Vasc Dis Res 6:190-193. 10.1177/1479164109336689

Ohneda K, Ee H, and German M. 2000. Regulation of insulin gene transcription. Semin Cell Dev Biol 11:227-233. 10.1006/scdb.2000.0171

Arcidiacono B, liritano S, Chiefari E, Brunetti FS, Gu G, Foti DP, and Brunetti A. 2014. Cooperation between HMGA1, PDX-1, and MafA is Essential for Glucose-Induced Insulin 
442 Transcription in Pancreatic Beta Cells. Front Endocrinol (Lausanne) 5:237.

$443 \quad 10.3389 /$ fendo.2014.00237

444 Shetty S, Chamukuttan S, Arun N, Jagannathan R, Sundaram S, and Ambady R. 2012. Influence

445 of BMI on Insulin Secretion and Insulin Sensitivity in Asian Indian Subjects With Impaired

$446 \quad$ Glucose Tolerance: Analysis of the Indian Diabetes Prevention Studies. American

447 Diabetes Association.

448 Greco M, Chiefari E, Montalcini T, Accattato F, Costanzo FS, Pujia A, Foti D, Brunetti A, and

449 Gulletta E. 2014. Early effects of a hypocaloric, Mediterranean diet on laboratory 450 parameters in obese individuals. Mediators Inflamm 2014:750860.

451 Grams J, and Garvey WT. 2015. Weight Loss and the Prevention and Treatment of Type 2 452 Diabetes Using Lifestyle Therapy, Pharmacotherapy, and Bariatric Surgery: Mechanisms 453 of Action. Curr Obes Rep 4:287-302. 10.1007/s13679-015-0155-x

454 Kekalainen P, Sarlund H, and Laakso M. 2000. Long-term association of cardiovascular risk 455 factors with impaired insulin secretion and insulin resistance. Metabolism 49:1247-1254. $456 \quad 10.1053 /$ meta.2000.9514

457

458 


\section{Table $\mathbf{1}$ (on next page)}

Clinical characteristics of participants by gender

Data are expressed as mean \pm SD, number (percentage) and median (interquartile ranges). “*” represented that the difference was significant. 
Table.1 Clinical characteristics of participants by gender

\begin{tabular}{cccc}
\hline & $\begin{array}{c}\text { Male } \\
(\mathrm{n}=252)\end{array}$ & $\begin{array}{c}\text { Female } \\
(\mathrm{n}=151)\end{array}$ & P-value \\
\hline Age $($ years $)$ & $47.97 \pm 13.09$ & $53.95 \pm 12.96$ & $<0.01^{*}$ \\
BMI $\left(\mathrm{kg} / \mathrm{m}^{2}\right)$ & $25.89 \pm 4.15$ & $24.85 \pm 4.21$ & $0.016^{*}$ \\
$\mathrm{SBP}(\mathrm{mmHg})$ & $127.77 \pm 16.26$ & $131.40 \pm 20.53$ & 0.065 \\
$\mathrm{DBP}(\mathrm{mmHg})$ & $80.37 \pm 11.37$ & $77.94 \pm 11.51$ & $0.04^{*}$ \\
FBG(mmol/L) & $9.58 \pm 3.5$ & $8.85 \pm 3.3$ & $0.039^{*}$ \\
2hPBG(mmol/L) & $19.34 \pm 5.49$ & $18.50 \pm 6.08$ & 0.153 \\
TC(mmol/L) & $4.82(4.18,5.58)$ & $4.87(4.19,5.66)$ & 0.432 \\
TG(mmol/L) & $1.94(1.36,3.46)$ & $1.84(1.23,2.71)$ & 0.096 \\
HDL-c(mmol/L) & $0.94(0.84,1.07)$ & $1.11(0.95,1.33)$ & $<0.01^{*}$ \\
LDL-c(mmol/L) & $3.02 \pm 0.83$ & $3.02 \pm 0.94$ & 0.985 \\
BUN(mmol/L) & $5.27 \pm 2.48$ & $4.73 \pm 1.40$ & $0.013^{*}$ \\
Scr( $\mu \mathrm{mol} / \mathrm{L})$ & $70.05(62.93,18.15)$ & $54 .(46.6,60.3)$ & $<0.01^{*}$ \\
UA( $\mu \mathrm{mol} / \mathrm{L})$ & $331.05(260.6,400.9)$ & $267.9(204.7,331.9)$ & $<0.01^{*}$ \\
Family history of T2DM & $28(11.3 \%)$ & $20(12.9 \%)$ & 0.478 \\
Smoking $(\%)$ & $107(42.5 \%)$ & $9(6 \%)$ & $<0.01^{*}$ \\
Consuming alcohol $(\%)$ & $70(27.8 \%)$ & $5(3.3)$ & $<0.01^{*}$ \\
\hline
\end{tabular}

2

Data are expressed as mean $\pm \mathrm{SD}$, number (percentage) and median (interquartile ranges). “*” represented that the difference was significant.

Abbreviations: UA: uric acid; BMI: body mass index; FPG, fasting plasma glucose; PBG, postprandial plasma glucose; TC: total cholesterol; TG: triglycerides, HDL-c: high-density lipoprotein-cholesterol; LDL: low-density lipoprotein-cholesterol; BUN: blood urea nitrogen; Scr: serum creatinine; SBP: systolic blood pressure; DBP: diastolic blood pressure. 


\section{Table 2 (on next page)}

Islet function indexes of all participants by gender

All continuous variables were presented as median (interquartile ranges) because of skewed distribution; the difference between groups was tested by Wilcoxon rank-sum test. "*" represented that the difference was significant. 


\begin{tabular}{cccl}
\hline & Male & Female & P-value \\
\hline HOMA-IR & $3.36(2.04 .5 .32)$ & $3.31(1.82,6.12)$ & 0.801 \\
ISI-composite & $74.95(49.24,111.89)$ & $65.62(39.99,119.63)$ & 0.076 \\
HOMA- $\beta$ & $31.52(16.76,71.27)$ & $40.14(18.37,84.13)$ & 0.122 \\
AUCins30/glu30min & $1.00(0.55,1.97)$ & $1.40(0.71,2.67)$ & $0.012^{*}$ \\
AUCins120/glu120min & $1.15(0.63,2.70)$ & $2.03(0.95,4.64)$ & $<0.01^{*}$ \\
DI30 & $68.24(48.82,126.06)$ & $81.30(53.62,128.23)$ & 0.175 \\
DI120 & $90.93(52.41,117.48)$ & $117.06(71.55,243.41)$ & $<0.01^{*}$ \\
\hline
\end{tabular}

3

4 All continuous variables were presented as median (interquartile ranges) because of skewed 5 distribution; the difference between groups was tested by Wilcoxon rank-sum test. "**" 6 represented that the difference was significant. 


\section{Table 3(on next page)}

Clinical characteristics and islet function indexes of male participants according to tertiles of serum uric acid levels

Data are expressed as mean $\pm S D$, number (percentage) and median (interquartile ranges).

aP: first tertile vs. second tertile, ${ }^{b} \mathrm{P}$ : first tertile vs. third teritile, ${ }^{\mathrm{C}} \mathrm{P}$ : second tertile vs. third tertile. "*" represented that the difference was significant. 


\begin{tabular}{|c|c|c|c|c|}
\hline \multicolumn{5}{|c|}{ Male } \\
\hline & first tertile $(n=84)$ & second tertile $(\mathrm{n}=85)$ & third tertile $(\mathrm{n}=83)$ & p-value \\
\hline $\mathrm{UA}(\mu \mathrm{mol} / \mathrm{L})$ standard & $\leq 279.7$ & $279.7-368.6$ & $\geq 368.8$ & \\
\hline Age (years) & $52.13 \pm 11.91$ & $46.85 \pm 11.91$ & $44.92 \pm 14.40$ & ${ }^{\mathrm{a}} \mathrm{P}^{*}=0.02,{ }^{\mathrm{b}} \mathrm{P} *<0.01,{ }^{\mathrm{c}} \mathrm{P}=0.6$ \\
\hline $\mathrm{BMI}(\mathrm{kg} / \mathrm{m} 2)$ & $24.87 \pm 3.27$ & $25.94 \pm 5.31$ & $26.87 \pm 3.33$ & ${ }^{\mathrm{a}} \mathrm{P}=0.2,{ }^{\mathrm{b}} \mathrm{P} *<0.01,{ }^{\mathrm{c}} \mathrm{P}=0.3$ \\
\hline $\mathrm{SBP}(\mathrm{mmHg})$ & $127.26 \pm 17.2$ & $127.33 \pm 14.60$ & $128.73 \pm 17.02$ & ${ }^{\mathrm{a}} \mathrm{P}=1.0,{ }^{\mathrm{b}} \mathrm{P}=0.8,{ }^{\mathrm{c}} \mathrm{P}=0.8$ \\
\hline $\mathrm{DBP}(\mathrm{mmHg})$ & $79.76 \pm 10.74$ & $79.16 \pm 11.25$ & $82.22 \pm 12.00$ & ${ }^{\mathrm{a} P}=0.9,{ }^{\mathrm{b}} \mathrm{P}=0.3,{ }^{\mathrm{c}} \mathrm{P}=0.2$ \\
\hline $\mathrm{FBG}(\mathrm{mmol} / \mathrm{L})$ & $10.35 \pm 3.25$ & $9.55 \pm 3.76$ & $8.84 \pm 3.34$ & $\mathrm{aP}=0.3,{ }^{b} \mathrm{P}^{*}=0.01, \mathrm{c}=0.4$ \\
\hline $2 \mathrm{hPBG}(\mathrm{mmol} / \mathrm{L})$ & $18.04 \pm 5.08$ & $16.03 \pm 6.11$ & $14.39 \pm 6.29$ & ${ }^{\mathrm{a}} \mathrm{P}=0.1,{ }^{\mathrm{b}} \mathrm{P}^{*}<0.01,{ }^{\mathrm{c}} \mathrm{P}=0.2$ \\
\hline $\mathrm{TC}(\mathrm{mmol} / \mathrm{L})$ & $4.71(4.06,5.55)$ & $4.62(4.09,5.48)$ & $5.06(4.50,5.68)$ & ${ }^{\mathrm{a}} \mathrm{P}=0.7,{ }^{\mathrm{b}} \mathrm{P}^{*}=0.04,{ }^{\mathrm{c}} \mathrm{P}^{*}=0.01$ \\
\hline $\mathrm{TG}(\mathrm{mmol} / \mathrm{L})$ & $1.71(1.30,2.35)$ & $1.88(1.26,3.18)$ & $2.65(1.68,4.54)$ & ${ }^{\mathrm{a}} \mathrm{P}=0.5,{ }^{\mathrm{b}} \mathrm{P} *<0.01,{ }^{\mathrm{c}} \mathrm{P}^{*}<0.01$ \\
\hline HDL-c(mmol/L) & $0.94(0.85,1.07)$ & $0.95(0.84,1.04)$ & $0.92(0.82,1.09)$ & ${ }^{\mathrm{a}} \mathrm{P}=0.6,{ }^{\mathrm{b}} \mathrm{P}=0.8,{ }^{\mathrm{c}} \mathrm{P}=0.9$ \\
\hline LDL-c $(\mathrm{mmol} / \mathrm{L})$ & $2.99 \pm 1.0$ & $3.02 \pm 0.81$ & $2.91 \pm 1.04$ & ${ }^{\mathrm{a}} \mathrm{P}=0.9,{ }^{\mathrm{b}} \mathrm{P}=0.8,{ }^{\mathrm{c}} \mathrm{P}=0.6$ \\
\hline $\mathrm{BUN}(\mathrm{mmol} / \mathrm{L})$ & $4.78 \pm 1.47$ & $5.37 \pm 1.67$ & $5.65 \pm 3.66$ & ${ }^{\mathrm{a}} \mathrm{P}=0.3,{ }^{\mathrm{b}} \mathrm{P}=0.06,{ }^{\mathrm{c}} \mathrm{P}=0.8$ \\
\hline $\operatorname{Scr}(\mu \mathrm{mol} / \mathrm{L})$ & $65(59.83,71.08)$ & $71.6(65.7,78.65)$ & $74.9(65.7,87)$ & ${ }^{\mathrm{a}} \mathrm{P}^{*}<0.01,{ }^{\mathrm{b}} \mathrm{P}^{*}<0.01,{ }^{\mathrm{c}} \mathrm{P}^{*}<0.01$ \\
\hline $\begin{array}{l}\text { family history of } \\
\text { T2DM }\end{array}$ & $8(9.5 \%)$ & $9(10.6 \%)$ & $11(13.3 \%)$ & ${ }^{\mathrm{a}} \mathrm{P}=0.8,{ }^{\mathrm{b}} \mathrm{P}=0.5,{ }^{\mathrm{c}} \mathrm{P}=0.6$ \\
\hline Smoking (\%) & $36(42.9 \%)$ & $36(42.4 \%)$ & $35(42.2)$ & ${ }^{\mathrm{a}} \mathrm{P}=0.9,{ }^{\mathrm{b}} \mathrm{P}=0.9,{ }^{\mathrm{c}} \mathrm{P}=1$ \\
\hline Drinking (\%) & $25(29.8)$ & $20(23.5 \%)$ & $25(30.1)$ & ${ }^{\mathrm{a}} \mathrm{P}=0.4,{ }^{\mathrm{b}} \mathrm{P}=0.9,{ }^{\mathrm{c}} \mathrm{P}=0.3$ \\
\hline \multicolumn{5}{|l|}{ Islet function indexes } \\
\hline HOMA-IR & $3.14(2.03,4.71)$ & $3.37(2.08,5.67)$ & $3.67(2.07,5.82)$ & ${ }^{\mathrm{a}} \mathrm{P}=0.8,{ }^{\mathrm{b}} \mathrm{P}=0.3, \mathrm{c} \mathrm{P}=0.5$ \\
\hline ISI-composit & $85.36(57.16,132.7)$ & $72.15(47.30,103.67)$ & $65.56(46.16,95.86)$ & ${ }^{\mathrm{a}} \mathrm{P}=0.2,{ }^{\mathrm{b}} \mathrm{P} *<0.01, \mathrm{c}=0.1$ \\
\hline НОМА- $\beta$ & $23.51(12.70,42.37)$ & $34.11(18.52,83.75)$ & $52.19(21.97,92.74)$ & ${ }^{\mathrm{a}} \mathrm{P}=0.1,{ }^{\mathrm{b}} \mathrm{P} *<0.01,{ }^{\mathrm{c}} \mathrm{P}^{*}=0.02$ \\
\hline AUCins30/glu30min & $0.8(0.46,1.25)$ & $1.07(0.60,2.25)$ & $1.59(0.74,2.60)$ & ${ }^{\mathrm{a}} \mathrm{P}=0.2,{ }^{\mathrm{b}} \mathrm{P} *<0.01,{ }^{\mathrm{c}} \mathrm{P}^{*}<0.01$ \\
\hline AUCins $120 /$ glu120min & $0.99(0.43,1.65)$ & $1.37(0.72,3.28)$ & $2.10(0.92,4.15)$ & ${ }^{\mathrm{a}} \mathrm{P}=0.1,{ }^{\mathrm{b}} \mathrm{P}^{*}<0.01,{ }^{\mathrm{c}} \mathrm{P}^{*}<0.01$ \\
\hline DI30 & $62.87(47.29,95.23)$ & $76.68(50.21,134.22)$ & $87.17(52.59,153.97)$ & ${ }^{\mathrm{a}} \mathrm{P}=0.3,{ }^{\mathrm{b}} \mathrm{P} *=0.01,{ }^{\mathrm{c}} \mathrm{P}=0.1$ \\
\hline DI120 & $69.7(47.59,118.58)$ & $93.59(53.22,209.58)$ & $105.30(59.11,220.3)$ & ${ }^{\mathrm{a}} \mathrm{P}=0.12,{ }^{\mathrm{b}} \mathrm{P} *<0.01,{ }^{\mathrm{c}} \mathrm{P}=0.1$ \\
\hline
\end{tabular}

Table.3 Clinical characteristics and islet function indexes of male participants according to tertiles of serum uric acid levels 


\section{Table 4 (on next page)}

Clinical characteristics and islet function indexes of female participants according to tertiles of serum uric acid levels

Data are expressed as mean $\pm S D$, number (percentage) and median (interquartile ranges).

aP: first tertile vs. second tertile, ${ }^{b P}$ : first tertile vs. third teritile, ${ }^{C P}$ : second tertile vs. third tertile. "*" represented that the difference was significant. 
1 Table.4 Clinical characteristics and islet function indexes of female participants according to

3

\begin{tabular}{|c|c|c|c|c|}
\hline & \multicolumn{4}{|c|}{ Female } \\
\hline & first tertile $(\mathrm{n}=50)$ & second tertile $(\mathrm{n}=50)$ & third tertile $(\mathrm{n}=51)$ & p-value \\
\hline $\mathrm{UA}(\mu \mathrm{mol} / \mathrm{L})$ standard & $\leq 224.1$ & $224.1-311.7$ & $\geq 311.7$ & \\
\hline Age (years) & $55.1 \pm 11.19$ & $52.38 \pm 13.36$ & $54.35 \pm 14.22$ & ${ }^{\mathrm{a}} \mathrm{P}=0.6,{ }^{\mathrm{b}} \mathrm{P}=0.1,{ }^{\mathrm{c}} \mathrm{P}=0.7$ \\
\hline $\mathrm{BMI}(\mathrm{kg} / \mathrm{m} 2)$ & $23.53 \pm 3.82$ & $24.75 \pm 4.37$ & $26.24 \pm 4.04$ & ${ }^{\mathrm{a}} \mathrm{P}=0.3,{ }^{\mathrm{b}} \mathrm{P}^{*}<0.01,{ }^{\mathrm{c}} \mathrm{P}=0.2$ \\
\hline $\mathrm{SBP}(\mathrm{mmHg})$ & $125.62 \pm 20.89$ & $132.28 \pm 18.71$ & $136.12 \pm 20.90$ & ${ }^{\mathrm{a}} \mathrm{P}=0.2,{ }^{\mathrm{b}} \mathrm{P}^{*}=0.03, \mathrm{c}=0.6$ \\
\hline $\mathrm{DBP}(\mathrm{mmHg})$ & $74.68 \pm 12.38$ & $78.44 \pm 10.52$ & $80.65 \pm 10.99$ & ${ }^{\mathrm{a}} \mathrm{P}=0.2,{ }^{\mathrm{b}} \mathrm{P} *=0.02, \mathrm{cP}=0.6$ \\
\hline $\mathrm{FBG}(\mathrm{mmol} / \mathrm{L})$ & $9.83 \pm 3.63$ & $8.57 \pm 3.19$ & $8.18 \pm 1.87$ & ${ }^{\mathrm{a}} \mathrm{P}=0.1,{ }^{\mathrm{b}} \mathrm{P}^{*}=0.03,{ }^{\mathrm{c}} \mathrm{P}=0.8$ \\
\hline 2hPBG(mmol/L) & $20.02 \pm 6.37$ & $18.18 \pm 5.98$ & $17.32 \pm 5.67$ & ${ }^{\mathrm{a}} \mathrm{P}=0.3,{ }^{\mathrm{b}} \mathrm{P}=0.06, \mathrm{cP}=0.8$ \\
\hline $\mathrm{TC}(\mathrm{mmol} / \mathrm{L})$ & $4.74(4.07,5.57)$ & $4.83(4.05,5.78)$ & $5.08(4.40 .5 .83)$ & ${ }^{\mathrm{a} P}=0.5,{ }^{\mathrm{b}} \mathrm{P}=0.1, \mathrm{cP}=0.4$ \\
\hline $\mathrm{TG}(\mathrm{mmol} / \mathrm{L})$ & $1.22(0.96,1.79)$ & $2.04(1.57,3.20)$ & $2.17(1.59,3.35)$ & ${ }^{\mathrm{a}} \mathrm{P}^{*}<0.01,{ }^{\mathrm{b}} \mathrm{P}^{*}<0.01,{ }^{\mathrm{c}} \mathrm{P}=0.6$ \\
\hline HDL-c(mmol/L) & $1.24(1.05,1.57)$ & $1.07(0.95,1.27)$ & $1.06(0.93,1.21)$ & ${ }^{\mathrm{a}} \mathrm{P}^{*}<0.01,{ }^{\mathrm{b}} \mathrm{P}^{*}<0.01,{ }^{\mathrm{c}} \mathrm{P}=0.6$ \\
\hline LDL-c(mmol/L) & $3.01 \pm 0.88$ & $3.06 \pm 1.07$ & $3.0 \pm 0.87$ & ${ }^{\mathrm{a}} \mathrm{P}=1,{ }^{\mathrm{b}} \mathrm{P}=1,{ }^{\mathrm{c}} \mathrm{P}=0.9$ \\
\hline $\mathrm{BUN}(\mathrm{mmol} / \mathrm{L})$ & $4.45 \pm 1.26$ & $4.53 \pm 1.17$ & $5.19 \pm 1.63$ & ${ }^{\mathrm{a}} \mathrm{P}=0.9,{ }^{\mathrm{b}} \mathrm{P} *=0.02,{ }^{\mathrm{c}} \mathrm{P} *=0.04$ \\
\hline $\operatorname{Scr}(\mu \mathrm{mol} / \mathrm{L})$ & $51.1(42.6,56.88)$ & $52.75(46.58,58.90)$ & $58.1(53.21,68.6)$ & ${ }^{\mathrm{a}} \mathrm{P}=0.3,{ }^{\mathrm{b}} \mathrm{P} *<0.01,{ }^{\mathrm{c}} \mathrm{P} *<0.01$ \\
\hline $\begin{array}{l}\text { family history of } \\
\text { T2DM }\end{array}$ & $8(16 \%)$ & $6(12 \%)$ & $7(13.7 \%)$ & ${ }^{\mathrm{a}} \mathrm{P}=0.6,{ }^{\mathrm{b}} \mathrm{P}=0.8,{ }^{\mathrm{c}} \mathrm{P}=0.8$ \\
\hline Smoking (\%) & $2(4 \%)$ & $4(8 \%)$ & $3(6 \%)$ & ${ }^{\mathrm{a}} \mathrm{P}=0.4,{ }^{\mathrm{b}} \mathrm{P}=0.7,{ }^{\mathrm{c}} \mathrm{P}=0.7$ \\
\hline Drinking (\%) & $3(6 \%)$ & $1(2 \%)$ & $1(2 \%)$ & ${ }^{\mathrm{a}} \mathrm{P}=0.3,{ }^{\mathrm{b}} \mathrm{P}=0.3,{ }^{\mathrm{c}} \mathrm{P}=1$ \\
\hline \multicolumn{5}{|l|}{ Islet function indexes } \\
\hline HOMA-IR & $2.56(1.59,5.14)$ & $3.21(1.25,6.69)$ & $3.71(2.65,6.81)$ & ${ }^{\mathrm{a}} \mathrm{P}=0.5,{ }^{\mathrm{b}} \mathrm{P}^{*}=0.01,{ }^{\mathrm{c}} \mathrm{P}=0.1$ \\
\hline ISI-composit & $88.85(48.42,141.69)$ & $68.50(35.91,143.65)$ & $57.83(35.72,76.360$ & ${ }^{\mathrm{a}} \mathrm{P}^{*}=0.03,{ }^{\mathrm{b}} \mathrm{P}^{*}<0.01,{ }^{\mathrm{c}} \mathrm{P}=0.3$ \\
\hline НОМА- $\beta$ & $22.35(9.78,59.99)$ & $46.15(20.63,86.43)$ & $49.29(29.17,130.84)$ & ${ }^{\mathrm{a}} \mathrm{P}=0.2,{ }^{b} \mathrm{P} *<0.01,{ }^{\mathrm{c}} \mathrm{P}=1$ \\
\hline AUCins30/glu30min & $0.81(0.37,1.99)$ & $1.49(0.72,2.75)$ & $1.69(1.06,3.18)$ & ${ }^{\mathrm{a}} \mathrm{P}^{*}=0.03,{ }^{\mathrm{b}} \mathrm{P}^{*}<0.01,{ }^{\mathrm{c}} \mathrm{P}=0.2$ \\
\hline AUCins $120 /$ glu120min & $1.23(0.52,3.15)$ & $2.10(1.06,4.00)$ & $2.80(1.59,5.62)$ & ${ }^{\mathrm{a}} \mathrm{P}^{*}=0.04,{ }^{\mathrm{b}} \mathrm{P} *<0.01,{ }^{\mathrm{c}} \mathrm{P}=0.1$ \\
\hline DI30 & $58.98(46.05,111.41)$ & $87.62(55.99,132.60)$ & $92.26(62.56,138.29)$ & ${ }^{\mathrm{a}} \mathrm{P}=0.1,{ }^{\mathrm{b}} \mathrm{P}^{*}=0.01, \mathrm{c} \mathrm{P}=0.6$ \\
\hline DI120 & $88.38(52.34,170.62)$ & $112.21(72.26,253.54)$ & 153.3(99.35,314.9) & ${ }^{\mathrm{a}} \mathrm{P}=0.1,{ }^{\mathrm{b}} \mathrm{P}^{*}<0.01,{ }^{\mathrm{c}} \mathrm{P}=0.4$ \\
\hline
\end{tabular}

$$
\text { tertiles of serum uric acid levels }
$$

Data are expressed as mean $\pm \mathrm{SD}$, number (percentage) and median (interquartile ranges). ap: first tertile vs. second tertile, bP: first tertile vs. third teritile, ${ }^{\mathrm{c}} \mathrm{P}$ : second tertile vs. third tertile. “*” represented that the difference was significant.

Abbreviations: UA: uric acid; BMI: body mass index; FPG, fasting plasma glucose; PBG, postprandial plasma glucose; TC: total cholesterol; TG: triglycerides, HDL-c: high-density lipoprotein-cholesterol; LDL: low-density lipoprotein-cholesterol; BUN: blood urea nitrogen; Scr: serum creatinine; SBP: systolic blood pressure; DBP: diastolic blood pressure. 


\section{Table 5 (on next page)}

Correlations between serum uric acid and islet function indexes by gender

“*” represented that the P-value was significant 
Table.5 Correlations between serum uric acid and islet function indexes by gender

2

\begin{tabular}{lccccc}
\hline \multirow{2}{*}{ Islet function indexes } & \multicolumn{2}{c}{ Male $(\mathrm{n}=252)$} & & \multicolumn{2}{c}{ Female $(\mathrm{n}=151)$} \\
\cline { 2 - 3 } \cline { 5 - 6 } & $\mathrm{r}$ & P-value & & $\mathrm{r}$ & P-value \\
\hline HOMA-IR & 0.09 & 0.14 & & 0.22 & $<0.01^{*}$ \\
ISI-composite & -0.24 & $<0.01^{*}$ & & -0.31 & $<0.01^{*}$ \\
HOMA- $\beta$ & 0.32 & $<0.01^{*}$ & & 0.28 & $<0.01^{*}$ \\
AUCins30/glu30 & 0.33 & $<0.01^{*}$ & & 0.32 & $<0.01^{*}$ \\
AUCins120/glu120 & 0.35 & $<0.01^{*}$ & & 0.33 & $<0.01^{*}$ \\
DI30 & 0.22 & $<0.01^{*}$ & & 0.19 & $0.02^{*}$ \\
DI120 & 0.26 & $<0.01^{*}$ & & 0.22 & $<0.01^{*}$ \\
\hline
\end{tabular}




\section{Table 6(on next page)}

Multiple linear regression analysis on related variables for islet function indexes in men

Categorical variables were family history (dichotomous: yes $=1$, no $=0$ ), smoking (dichotomous: yes $=1$, no $=0$ ) and drinking (dichotomous: yes $=1$, no $=0$ ). P value derived from stepwise multiple linear regression analysis. Only the variables whose $P<0.05$ were shown in the table. 
1 Table.6 Multiple linear regression analysis on related variables for islet function indexes in men 2

\begin{tabular}{|c|c|c|c|c|}
\hline $\begin{array}{l}\text { Islet function } \\
\text { indexes }\end{array}$ & $\begin{array}{l}\text { Partical regerssion } \\
\text { coefficient(B) }\end{array}$ & $\begin{array}{l}\text { Standard } \\
\text { error }(\mathrm{SE})\end{array}$ & $\begin{array}{c}\text { Standard paricial } \\
\text { regerssion } \\
\text { coefficient }(\beta)\end{array}$ & P-value \\
\hline HOMA-IR & No variable & were enterec & nto the equation & \\
\hline \multicolumn{5}{|l|}{ ISI-composite } \\
\hline BMI & -4.36 & 1.02 & -0.26 & $<0.01$ \\
\hline \multicolumn{5}{|l|}{ НОМА- $\beta$} \\
\hline Scr & 1.48 & 0.69 & 0.134 & 0.03 \\
\hline \multicolumn{5}{|l|}{ AUCins30/glu30 } \\
\hline UA & 0.004 & 0.001 & 0.241 & $<0.01$ \\
\hline BMI & 0.077 & 0.025 & 0.188 & $<0.01$ \\
\hline DBP & 0.019 & 0.009 & 0.129 & 0.03 \\
\hline age & 0.017 & 0.008 & 0.128 & 0.04 \\
\hline \multicolumn{5}{|c|}{ AUCins120/glu120 } \\
\hline UA & 0.007 & 0.001 & 0.334 & $<0.01$ \\
\hline DBP & 0.037 & 0.012 & 0.174 & $<0.01$ \\
\hline TG & -0.117 & 0.045 & -0.151 & 0.01 \\
\hline BMI & 0.098 & 0.035 & 0.169 & $<0.01$ \\
\hline age & 0.023 & 0.011 & 0.122 & 0.04 \\
\hline \multicolumn{5}{|l|}{ DI30 } \\
\hline UA & 0.163 & 0.048 & 0.216 & $<0.01$ \\
\hline $\mathrm{TC}$ & -11.84 & 3.8 & -0.185 & $<0.01$ \\
\hline Scr & 0.841 & 0.338 & 0.158 & $<0.01$ \\
\hline SBP & 0.63 & 0.303 & 0.123 & 0.04 \\
\hline \multicolumn{5}{|l|}{ DI120 } \\
\hline UA & 0.346 & 0.08 & 0.272 & $<0.01$ \\
\hline $\mathrm{TC}$ & -19.58 & 6.31 & -0.181 & $<0.01$ \\
\hline SBP & 1.205 & 0.514 & 0.139 & 0.02 \\
\hline Scr & 1.327 & 0.562 & 0.149 & 0.02 \\
\hline
\end{tabular}

3

4 Categorical variables were family history (dichotomous: yes $=1$, no $=0$ ), smoking (dichotomous: 5 yes $=1$, no $=0$ ) and drinking (dichotomous: yes $=1$, no $=0$ ). $\mathrm{P}$ value derived from stepwise 6 multiple linear regression analysis. Only the variables whose $\mathrm{P}<0.05$ were shown in the table.

7 Abbreviations: UA: uric acid; BMI: body mass index; TC: total cholesterol; TG: triglycerides;

8 Scr: serum creatinine; SBP: systolic blood pressure; DBP: diastolic blood pressure. 


\section{Table 7 (on next page)}

Multiple linear regression analysis on related variables for islet function indexes in women

Categorical variables were family history (dichotomous: yes $=1$, no $=0$ ), smoking

(dichotomous: yes $=1$, no $=0$ ) and drinking (dichotomous: yes $=1$, no $=0$ ). P value derived from stepwise multiple linear regression analysis. Only the variables whose $P<0.05$ were shown in the table. 
1 Table.7 Multiple linear regression analysis on related variables for islet function indexes in 2 women

\begin{tabular}{|c|c|c|c|c|}
\hline $\begin{array}{l}\text { Islet function } \\
\text { indexes }\end{array}$ & $\begin{array}{l}\text { Partical regerssion } \\
\text { coefficient(B) }\end{array}$ & $\begin{array}{l}\text { Standard } \\
\text { error }(\mathrm{SE})\end{array}$ & $\begin{array}{c}\text { Standard paricial } \\
\text { regerssion } \\
\text { coefficient }(\beta)\end{array}$ & P-value \\
\hline \multicolumn{5}{|l|}{ HOMA-IR } \\
\hline BMI & 0.215 & 0.054 & 0.308 & $<0.01$ \\
\hline \multicolumn{5}{|l|}{ ISI-composite } \\
\hline BMI & -6.22 & 1.09 & -0.422 & $<0.01$ \\
\hline НОМА- $\beta$ & \multicolumn{4}{|c|}{ No variable were entered into the equation } \\
\hline \multicolumn{5}{|l|}{ AUCins30/glu30 } \\
\hline UA & 0.004 & 0.001 & 0.263 & $<0.01$ \\
\hline \multicolumn{5}{|c|}{ AUCins120/glu120 } \\
\hline UA & 0.009 & 0.002 & 0.296 & $<0.01$ \\
\hline DI30 & \multicolumn{4}{|c|}{ No variable were entered into the equation } \\
\hline \multicolumn{5}{|l|}{ DI120 } \\
\hline UA & 2.844 & 1.302 & 0.191 & 0.03 \\
\hline
\end{tabular}

3

4 Categorical variables were family history (dichotomous: yes $=1$, no $=0$ ), smoking (dichotomous: 5 yes $=1$, no $=0$ ) and drinking (dichotomous: yes $=1$, no $=0$ ). $\mathrm{P}$ value derived from stepwise 6 multiple linear regression analysis. Only the variables whose $\mathrm{P}<0.05$ were shown in the table.

7 Abbreviations: UA: uric acid; BMI: body mass index.

8

9 


\section{Table 8 (on next page)}

Serum uric acid and islet function indexes of all participants according to BMI in male and female.

Data are expressed as median (interquartile ranges). aP: first tertile vs. second tertile, ${ }^{\mathrm{b} P}$ : first tertile vs. third teritile, ${ }^{c P}$ : second tertile vs. third tertile. “*” represented that the difference was significant. 


\begin{tabular}{|c|c|c|c|c|c|c|c|c|}
\hline & \multicolumn{3}{|c|}{ male } & \multicolumn{5}{|c|}{ female } \\
\hline & $\begin{array}{l}\text { normol weight } \\
(\mathrm{BMI}<23 \mathrm{~kg} / \mathrm{m} 2)\end{array}$ & $\begin{array}{l}\text { overweight } \\
(\mathrm{BMI}: 23-24.9 \mathrm{~kg} / \mathrm{m} 2)\end{array}$ & $\begin{array}{l}\text { Obesity } \\
\mathrm{BMI} \geq 25 \mathrm{~kg} / \mathrm{m} 2\end{array}$ & p-value & $\begin{array}{l}\text { normol weight } \\
(\mathrm{BMI}<23 \mathrm{~kg} / \mathrm{m} 2)\end{array}$ & $\begin{array}{l}\text { overweight } \\
\text { (BMI:23-24.9kg/m2) }\end{array}$ & $\begin{array}{l}\text { obesity } \\
\mathrm{BMI} \geq 25 \mathrm{~kg} / \mathrm{m} 2\end{array}$ & p-value \\
\hline $\mathrm{UA}(\mu \mathrm{mol} / \mathrm{L})$ & $300.2(226.6,251.7)$ & $279.7(227.4,343.4)$ & $359.1(280.6,438.9)$ & $\begin{array}{l}{ }^{\mathrm{a}} \mathrm{P}=0.3 \\
{ }^{\mathrm{b}} \mathrm{P}=0.001 * \\
{ }^{\mathrm{C}} \mathrm{p}<0.001 *\end{array}$ & $250.4(193.5,303.7)$ & $249.8(203.1,318.8)$ & $299.8(227.9,404.7)$ & $\begin{array}{c}{ }^{\mathrm{a}} \mathrm{P}=0.4 \\
{ }^{\mathrm{b}} \mathrm{P}<0.001^{*} \\
{ }^{\mathrm{c}} \mathrm{P}=0.02 *\end{array}$ \\
\hline Islet function indexes & & & & & & & & \\
\hline HOMA-IR & $2.1(1.5,4.4)$ & $3.1(2.0,4.1)$ & $4.0(2.4,6.3)$ & $\begin{array}{l}{ }^{\mathrm{a}} \mathrm{P}=0.06 \\
{ }^{\mathrm{b}} \mathrm{P}<0.001 * \\
{ }^{\mathrm{c}} \mathrm{P}=0.008^{*}\end{array}$ & $2.7(1.3,4.0)$ & $2.9(1.6,4.8)$ & $5.1(2.7,7.4)$ & $\begin{array}{l}{ }^{\mathrm{a}} \mathrm{P}=0.7 \\
{ }^{\mathrm{b}} \mathrm{P}<0.001^{*} \\
{ }^{\mathrm{c}} \mathrm{P}=0.005^{*}\end{array}$ \\
\hline ISI-composit & $103.4(71.2,154.3)$ & $86.1(65.2,116.7)$ & $61.9(45.3,98.3)$ & $\begin{array}{l}{ }^{\mathrm{a}} \mathrm{P}=0.3 \\
{ }^{\mathrm{b}} \mathrm{P}<0.001 * \\
{ }^{\mathrm{c}} \mathrm{P}=0.001 *\end{array}$ & $89.5(61.7,157.7)$ & $68.8(52.4,118.6)$ & $44.1(32.6,75.4)$ & $\begin{array}{l}{ }^{\mathrm{a}} \mathrm{P}=0.1 \\
{ }^{\mathrm{b}} \mathrm{P}<0.001^{*} \\
{ }^{\mathrm{c}} \mathrm{P}<0.001^{*}\end{array}$ \\
\hline НОМА- $\beta$ & $19.2(10.8,36.2)$ & $26.1(13.5,44.1)$ & $42.7(20.2,88.6)$ & $\begin{array}{l}{ }^{\mathrm{a}} \mathrm{P}=0.1 \\
{ }^{\mathrm{b}} \mathrm{P}<0.001 * \\
{ }^{\mathrm{c}} \mathrm{P}=0.001 *\end{array}$ & $27.1(11.7,43.6)$ & $39.7(14.7,75.3)$ & $66.3(28.1,138.3)$ & $\begin{array}{l}{ }^{\mathrm{a}} \mathrm{P}=0.1 \\
{ }^{\mathrm{b}} \mathrm{P}<0.001^{*} \\
{ }^{\mathrm{c} P}=0.007^{*}\end{array}$ \\
\hline AUCins30/glu30min & $0.6(0.4,1.1)$ & $0.8(0.5,1.2)$ & $1.3(0.8,2.3)$ & $\begin{array}{l}{ }^{\mathrm{a}} \mathrm{P}=0.2 \\
{ }^{\mathrm{b}} \mathrm{P}<0.001 * \\
{ }^{\mathrm{c}} \mathrm{P}<0.001 *\end{array}$ & $0.8(0.4,1.7)$ & $1.2(0.5,2.0)$ & $2.4(1.2,3.3)$ & $\begin{array}{l}{ }^{\mathrm{a}} \mathrm{P}=0.2 \\
{ }^{\mathrm{b}} \mathrm{P}<0.001^{*} \\
{ }^{\mathrm{c}} \mathrm{P}=0.002 *\end{array}$ \\
\hline AUCins120/glu120min & $0.8(0.4,1.6)$ & $1.0(0.5,1.6)$ & $1.7(0.8,3.5)$ & $\begin{array}{l}{ }^{\mathrm{a}} \mathrm{P}=0.5 \\
{ }^{\mathrm{b}} \mathrm{P}<0.001 * \\
{ }^{\mathrm{c}} \mathrm{P}=0.001 *\end{array}$ & $1.2(0.5,2.1)$ & $2.1(0.9,4.4)$ & $3.6(1.5,5.6)$ & $\begin{array}{l}{ }^{\mathrm{a}} \mathrm{P}=0.03 * \\
{ }^{\mathrm{b}} \mathrm{P}<0.001^{*} \\
{ }^{\mathrm{c} P}=0.01 *\end{array}$ \\
\hline DI30 & $59.7(43.2,114.4)$ & $62.9(43.2,95.9)$ & $82.1(52.1,146.6)$ & $\mathrm{aP}=0.9$ & $71.0(46.7,100.3)$ & $81.3(53.7,134.7)$ & $93.5(56.2,158.6)$ & ${ }^{\mathrm{a}} \mathrm{P}=0.3$ \\
\hline
\end{tabular}




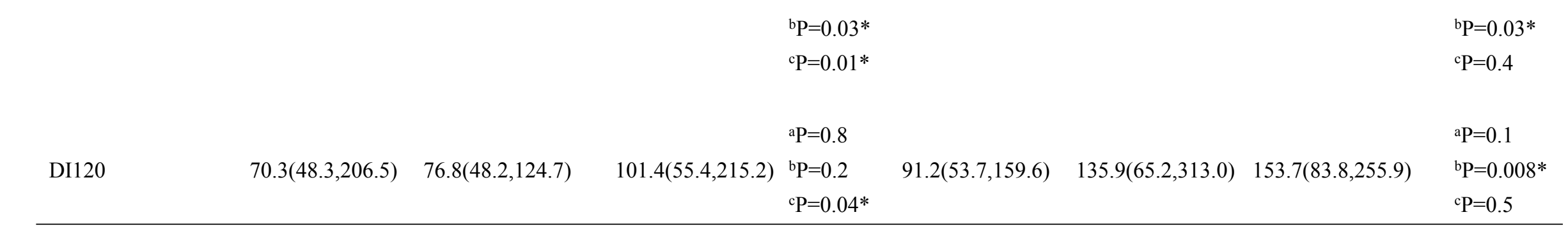

3

4 Data are expressed as median (interquartile ranges). ${ }^{\text {aP: }}$ first tertile vs. second tertile, bP: first tertile vs. third teritile, ${ }^{\mathrm{c} P}$ : second tertile

5 vs. third tertile. "*” represented that the difference was significant. 